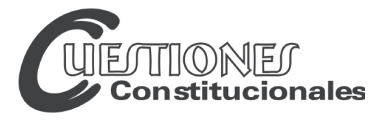

Revista Mexicana de Derecho Constitucional

Núm. 26, enero-junio 2012

\title{
LA CORRESPONSABILIDAD COMO PRINCIPIO CONSTITUCIONAL EN VENEZUELA
}

\section{JOINT RESPONSIBILITY AS A CONSTITUTIONAL PRINCIPLE IN VENEZUELA}

\section{Aurora AnZola NiEves*}

RESUMEN: Esta investigación estudia el principio de corresponsabilidad previsto en la Constitución venezolana de 1999, a través de la metodología cualitativa. Se presenta un marco comprensivo de la Doctrina particular del Estado a través de perspectivas socio-históricas, jurídicas y políticas que contribuyen a una incursión sobre el deber-ser de las acciones del Estado en atención a las previsiones constitucionales venezolanas. Se realiza la interpretación de la Doctrina Particular del Estado, que se refiere al estudio, comprensión y análisis desde el punto de vista de la evolución histórica de un Estado particular: Venezuela. La Constitución venezolana de 1999 replantea la relación del Estado con la sociedad en Venezuela, específicamente, en cuanto al papel de la sociedad civil frente al principio constitucional de corresponsabilidad. La corresponsabilidad como uno de los principios constitucionales que sustenta el modelo de Estado y de sociedad en Venezuela, se entiende como el principio en donde el Estado tiene unas funciones y responsabilidades que le son propias, y la sociedad civil tiene unos derechos pero también obligaciones que cumplir en los asuntos públicos, los cuales se ejercen corresponsablemente.

Palabras clave: Constitución, principios constitucionales, corresponsabilidad.
ABSTRACT: This investigation studies the principle of shared responsibility referred to in the 1999 Venezuelan Constitution, through qualitative methodology. It presents a comprehensive framework for the Doctrine of the particular state through socio-historical perspectives, legal and political that contributes to a raid on the must-be state action in attention to Venezuelan constitutional provisions. It makes the interpretation of the particular doctrine of the State, which refers to the study, understanding and analysis from the point of view of historical evolution of a particular State, Venezuela. The Venezuelan Constitution of 1999 redefines the relationship between the state and society in Venezuela, specifically regarding the role of civil society front the constitutional principle of shared responsibility. Joint responsibility as one of the constitutional principles behind the model of state and society in Venezuela, is understood as the principle on which the state has some functions and responsibilities that are proper and civil society has rights but also obligations meet in public affairs, which are exercised jointly responsible.

Descriptors: Constitution, constitutional principles, joint responsibility.

* Docente e Investigadora del Decanato de Administración y Contaduría en la Universidad Centroccidental Lisandro Alvarado en Barquisimeto-Venezuela. 


\section{INTRODUCCIÓN}

Esta investigación tiene como punto de partida los planteamientos que recoge la Constitución venezolana de 1999 (CRBV), ${ }^{1}$ en cuanto al principio de corresponsabilidad entre la sociedad civil y el Estado venezolano. La Constitución vigente en Venezuela señala, en ocasión del principio de corresponsabilidad, nuevos roles, nuevas obligaciones, nuevos derechos y herramientas a la sociedad civil venezolana que la lleva a involucrarse en los asuntos públicos e impone al Estado el deber de garantizar, impulsar y facilitar la concreción de los derechos de la sociedad civil y a la vez los deberes y obligaciones de ésta en los asuntos públicos. Ello replantea, en lo formal, la relación de la sociedad civil con el Estado y redimensiona la tradicional dicotomía entre éstos.

La idea del derecho de la que parte esta investigación no se limita a un conjunto de normas escritas por y para una sociedad dada, en este caso, la sociedad venezolana. El derecho se considera un fenómeno social complejo en el que interactúan los principios, los valores, las normas, y a partir de esta idea del derecho se interpreta lo formalmente propuesto en la Constitución venezolana de 1999, así como las posiciones teórico-conceptuales.

En este sentido, se identifican los antecedentes de la actual concepción del Estado venezolano a través de breves consideraciones sobre su origen y transformación, y se analiza la redefinición del Estado venezolano constitucionalmente prevista y los principios constitucionales formalmente consagrados en la Constitución venezolana de 1999 (CRBV), ${ }^{2}$ concretamente, en cuanto al principio de corresponsabilidad.

\section{ORIGEN Y TRANSFORMACIÓN DEL ESTADO DE DERECHO EN VENEZUELA}

El Estado venezolano - tanto en lo institucional como en lo jurídiconace bajo una concepción de Estado de derecho. De forma más reciente, la

1 Constitución de la República Bolivariana de Venezuela (CRBV). Gaceta Oficial 5.453 del 24 de marzo de 2000. Segunda versión. Caracas, Venezuela.

2 Constitución de la República Bolivariana de Venezuela (CRBV), op. cit. 
concepción que se le otorga en la vigente Constitución de 1999 (CRBV), ${ }^{3}$ es de Estado social y democrático de derecho y de justicia.

En la actual concepción de Estado se le reconocen derechos sociales básicos a la ciudadanía, tales como: salud, educación, vivienda, alimentación, trabajo; en un marco regulatorio constitucional y legal que prevé los medios, vías e instrumentos a través de los cuales pueden materializarse los mismos.

Inicialmente, estos derechos se reconocen en Constituciones anteriores a la de 1999, cuando Venezuela comienza a transitar por el constitucionalismo moderno. Deriva de este nuevo constitucionalismo, tal como lo señala Martínez "...la concreción de importantes modificaciones a la estructura económica, social y jurídica, por lo que representa también instaurar y ejecutar mecanismos que protejan los derechos sociales".

Actualmente al texto constitucional venezolano (CRBV) se le denomina "Constitución Social", pues consagra no sólo los derechos sociales — que ya estaban garantizados y previstos en Constituciones anteriores, tales como por ejemplo, la de 1947 y la de 1961 - sino porque existe una marcada tendencia a la garantía y defensa de estos derechos a los venezolanos en la vigente Constitución (Escarrá, ${ }^{5}$ Pulido de Briceño). ${ }^{6}$

Ahora bien, ¿cómo se entiende la actual concepción de Estado que contempla la Constitución venezolana de $1999(\mathrm{CRBV})$ ? ¿Cómo se relaciona el principio de corresponsabilidad con la concepción de Estado que presenta la Constitución de 1999 (CRBV)? ¿Cómo contempla la Constitución vigente (CRBV) el principio de corresponsabilidad? ¿Cómo se diferencia la propuesta de la Constitución venezolana de 1999 (CRBV, 1999) de las propuestas de las Constituciones anteriores, en cuanto al principio de corresponsabilidad? A estas preguntas se les da respuesta en los puntos subsiguientes.

3 Ibidem, artículo 20.

4 Martínez, Agustina Yadira, "Los derechos sociales en la nueva Constitución: sus mecanismos de protección", El nuevo derecho constitucional venezolanúm. Ponencias IV Congreso Derecho Constitucional en homenaje al Dr. Humberto La Roche, Venezuela, UCAB, 2001, pp. 351-364, especialmente p. 353.

5 Escarrá Malavé, Carlos, "Las transformaciones en los fundamentos de la democracia y el nuevo campo de fuerza y poder”, Seminario Nacional: Política Social ¿un nuevo PARADIGMA?, Caracas, Fundación Escuela de Gerencia Social, 2004 en http://www. gerenciasocial.org.ve/bsocial/bs_03/bs_03_pdf_doc/martes/panel_carlos_escarra.pdf.

6 Pulido de Briceño, Mercedes, "La Constitución de 1999 y los derechos sociales", en Maingon, Thais (coord.), La cuestión social en la Constitución Bolivariana de Venezuela, Serie Temas de Docencia, Venezuela, Editorial Torino, 2000, pp. 15-28. 


\section{El Estado venezolano en la Constitución de 1999}

La Constitución venezolana de 1999 (CRBV), la cual surge de un proceso constituyente que culminó el 15 de diciembre de 1999, 7 incorpora por primera vez en la historia constitucional venezolana lo referente al Estado social. ${ }^{8}$ Se constituye Venezuela de manera expresa y formal como un Estado social de derecho y de justicia en los términos que señala el artículo 2 de la Constitución venezolana vigente (CRBV), el cual contempla que:

7 El proceso constituyente por el cual transitó Venezuela en 1999 y a través del cual se aprobó la vigente Constitución (CRBV) se originó de cara a grandes expectativas que los venezolanos tenían frente al agotamiento del modelo político presente en ese momento. Para ampliar el debate y planteamientos que guardan relación con el proceso constituyente venezolano de 1999, ver el tema en Brewer-Carías, Allan, Constitución de la República Bolivariana de Venezuela. Comentarios, Caracas, Editorial Jurídica Venezolana, 2000; Brewer-Carías, Allan, "Reflexiones críticas sobre la Constitución de Venezuela de 1999", en Carbonell Sánchez, Miguel y Valdés, Diego, Constitucionalismo iberoamericano en el Siglo XXI, México, UNAM, 2000, en http://dialnet.unirioja.es/servlet/ libro? codigo=2089; Combellas, Ricardo, "El proceso constituyente y la Constitución de 1999”, Revista Venezolana de Ciencia Política, Mérida, núm. 22, julio-diciembre de 2002. Centro de Investigaciones de Política Comparada. Postgrado de Ciencia Política. ULA, pp. 9-30; Combellas, Ricardo, "La Constitución de 1999 y la Reforma Política. Implicaciones para la gobernabilidad democrática", Revista Venezolana de Ciencia Política, Mérida, núm. 22, julio-diciembre de 2002, Centro de Investigaciones de Política Comparada. Postgrado de Ciencia Política. ULA. Combellas, Ricardo, Derecho constitucional. Una introducción al estudio de la Constitución Bolivariana de Venezuela, Caracas, McGraw-Hill; Escarrá Malavé, Carlos, "Los mecanismos de participación ciudadana como garantía de la soberanía popular en la Constitución de la República Bolivariana de Venezuela", ponencia presentada en las Primeras Jornadas de Derecho Electoral y Procesos Democráticos de Participación, Universidad Católica Andrés Bello, 5 y 6 de febrero de 2003, http://www.imca.org.ve/Dr_Carlos_Escarra.htm; Fernández Toro, Julio César, "Los problemas constitucionales de la institucionalización democrática en Venezuela: 1972-2002”, Politeia, enero de 2003, vol. 26, núm. 30, pp. 114-142; Casal, Jesús María y Chacón, Alma (coords.), El nuevo derecho constitucional venezolano, Caracas, núm. 2001, UCAB; Istúriz, Aristóbulo, "Lo social en la nueva Constitución Bolivariana", en Maingon, Thais (coord.), La cuestión social en la Constitución Bolivariana de Venezuela, Serie Temas de Docencia, Venezuela, Editorial Torino, núm. 2000, pp. 1-14; Viciano Pastor, Roberto y Martínez Dalmau, Rubén, Cambio político y proceso constituyente en Venezuela (1998-2000), Venezuela, Vadell Hermanos Editores, 2001, entre otros.

8 Ello no quiere decir que Venezuela con anterioridad no era - materialmente - un Estado social. Desde 1947, la Constitución previó el carácter social del Estado venezolano pero sin proclamarlo de forma expresa. Autores como Combellas, Brewer Carías, García Pelayo, Fernández T., entre otros, dan cuenta de esto en sus innumerables trabajos. 
Venezuela se constituye en un Estado democrático y social de Derecho y de Justicia, que propugna como valores superiores de su ordenamiento jurídico y de su actuación, la vida, la libertad, la justicia, la igualdad, la solidaridad, la democracia, la responsabilidad social y en general, la preeminencia de los derechos humanos, la ética y el pluralismo político (CRBV). ${ }^{9}$

La Exposición de Motivos de la Constitución de la República Bolivariana de Venezuela de 1999 (EMCRBV), ${ }^{10}$ en el título I, sobre los principios fundamentales, expresa: primero, respecto a la organización jurídico-política, que la Nación venezolana adopta un Estado democrático social de derecho y de justicia, así como los valores superiores del ordenamiento jurídico del Estado, por cuanto, es éste quien debe propugnar el bienestar de los venezolanos "...creando las condiciones necesarias para su desarrollo social y espiritual, y procurando la igualdad de oportunidades para que todos los ciudadanos puedan desarrollar libremente su personalidad, dirigir su destino, disfrutar los derechos humanos y buscar su felicidad" (EMCRBV). ${ }^{11}$

Segundo, deja sentado el rol que debe asumir tanto la sociedad como el Estado, puesto que, “...las personas y los grupos sociales han de empeñarse en la realización y ejercicio de sus derechos y en el cumplimiento de sus deberes, mientras que el Estado es un instrumento para la satisfacción de tales fines" (EMCRBV). ${ }^{12}$

Al respecto, la Exposición de Motivos de la Constitución de la República Bolivariana de Venezuela de 1999 (EMCRBV) dice que éste

...se nutre de la voluntad de los ciudadanos, expresada libremente por los medios de participación política y social para conformar el Estado democrático. Estado social y democrático de Derecho comprometido con el progreso integral que los venezolanos aspiran, con el desarrollo humano que permita una calidad de vida digna, aspectos que configuran el concepto de Estado de Justicia. Se corresponde esta definición con una serie de las principales motivaciones expresadas en el Preámbulo, es decir, el fin supremo de refundar la República para establecer una sociedad democrática. Ya no sólo es el Estado el que debe ser democrático, sino también la sociedad. Siendo democrática

9 Constitución de la República Bolivariana de Venezuela (CRBV), artículo 2, op. cit.

10 Exposición de Motivos de la Constitución de la República Bolivariana de Venezuela (EMCRBV). Gaceta Oficial 5.453, extraordinario del 24 de marzo de 2000. Segunda versión, Caracas, Venezuela.

11 Exposición de Motivos de la Constitución de la República Bolivariana de Venezuela. (EMCRBV), artículo 2, op. cit., p. 1.

12 Idem. 
la sociedad, todos los elementos que la integran deben estar signados por los principios democráticos y someterse a ellos (EMCRBV). ${ }^{13}$

En este sentido, la Constitución venezolana de 1999 (CRBV) presenta una propuesta ${ }^{14}$ en la que se consagra la reestructuración del Estado venezolano en todos sus ámbitos, como antes se refirió y plantea una nueva realidad en lo jurídico-institucional, a partir de su consagración como Estado social de derecho y de Justicia.

13 Idem.

14 La propuesta que trae la nueva Constitución (CRBV, 1999), tiene diferentes formas de entenderse y hasta de justificarse. Ello en atención de la realidad política presente en Venezuela y a la polarización política y social que existe. Están presentes dos visiones que se contraponen y que les lleva a fijar posiciones antagónicas en cuanto a si la reestructuración del Estado venezolano a través de la Constitución de 1999 (CRBV, 1999) procura o no la superación de la crisis político-social que le dio origen. La polarización política y social no se tratará en este trabajo, por cuanto no constituye su objeto de estudio. No obstante, cabe señalar que existe una amplia gama de estudios, de investigaciones que tratan — directa o indirectamente - sobre este aspecto. Entre otros están Boersner, "Venezuela: polarización, abstención y elecciones", Revista Nueva Sociedad, edición especial, marzo de 2006; Combellas, R., "Representación versus participación en la Constitución de la República Bolivariana de Venezuela. Análisis de un falso dilema”, en Salamanca, Luis y Viciano Pastor, Roberto (coords.). El sistema politico en la Constitución Bolivariana de Venezuela, Vadell Hermanos, 2004; Salas. 2004; Álvarez, A., "La reforma del Estado antes y después de Chávez", en Ellner y Hellinger, D. (eds.), La política venezolana en la época de Chávez. Clases, polarización y conflicto, Caracas, Nueva Sociedad, 2003; García G., "Politización y polarización de la sociedad civil venezolana: las dos caras frente a la democracia", Revista Espacio Abierto, vol. 12, núm. 1, marzo de 2003; Medina y López Maya, Venezuela: confrontación social y polarización politica, 2003; Arenas, N. y Gómez Calcaño, L., El imaginario redentor: de la Revolución de Octubre a la Quinta República, Caracas, CENDES. Temas para la discusión, serie arbitrada, 2003. En relación con las posiciones que plasman puntos de vistas contrarios y son el reflejo de la polarización que antes se señaló, estas visiones gozan del respaldo de estudiosos, de investigadores en materia constitucional, de la ciencia política, de la sociología política, de la historia, entre otras. Esta investigación se limita a mencionar - en general - ambas posiciones, por cuanto dicha discusión va más allá del planteamiento, del objeto de estudio de este trabajo. Entre los constitucionalistas patrios que han tenido y tienen una relación estrecha con la promulgación y ejecución de la actual Constitución y que en general, recogen desde sus perspectivas estos puntos de vista, se tienen a Escarrá, Brewer Carias, Combellas, entre otros, a través de sus prolíficas obras e investigaciones. Finalmente, en cuanto a las discusiones que se refieren a la contradicción o complementariedad de un Estado que se proclama a la vez social, de derecho y de justicia, ver para ampliar este punto, Hernández, "Estado social y ordenación constitucional del sistema económico venezolano", en 2006. http://www.juridicas.unam.mx/publica/librev/rev/dconstla/cont/20061/pr/pr14.pdf. 
Esta configuración que expresamente se consagra en la Constitución de 1999 (CRBV), atiende a la tradición del constitucionalismo contemporáneo, “tal como está expresado, por ejemplo, en la Constitución española (artículo 1), en la Constitución de Colombia (artículo 1), y en la Constitución de la República Federal Alemana (artículo 20,1)". ${ }^{15}$

La idea de Estado Social es la de un Estado con obligaciones sociales, un Estado de procura de la justicia social, lo que lo lleva a intervenir en la actividad económica y social, como un Estado prestacional. En este sentido, el constituyente venezolano en 1999 al plantear el Estado venezolano como social de derecho y de Justicia, atiende al contemporáneo constitucionalismo democrático. Para comprender este tipo de Estado, Combellas ${ }^{16}$ lo analiza a través de notas definitorias: la nota social, la nota jurídica y la nota democrática.

En cuanto a la nota social, el Estado Social es “.... antitético a las nociones de Estado mínimo y Estado abstencionista, cónsonas con la rancia tradición liberal... Los derechos sociales...son derechos fundamentales por los cuales debe velar positivamente el Estado...". ${ }^{17}$

En relación a la nota democrática, Venezuela al consagrarse como un Estado democrático "por una parte, tiene como presupuesto y obligación el coadyuvar al establecimiento de una sociedad democrática, y por la otra, abrir su estructura burocrática a la participación ciudadana". ${ }^{18}$ Ello en atención de que este Estado se rige por el principio de la democracia participativa.

En lo atinente a la nota jurídica, la Constitución prevé un Estado de derecho y de justicia, lo cual se considera casual, por cuanto ello implica la subordinación y hasta la superación en la interpretación del derecho en aras de alcanzar y concretar a la justicia. La Constitución venezolana de 1999 (CRBV, 1999) "pauta una serie de exigencias para que el derecho esté al servicio de la justicia (véanse, de manera especial, los artículos 26, 27 y 257 CB)...". ${ }^{19}$

El Tribunal Supremo de Justicia, por su parte, entiende las notas definitorias del Estado social venezolano, tal como lo señala en sentencia de 2002, cuando expresa que:

15 Brewer-Carías, A., op. cit., p. 47.

16 Combellas, R., op. cit.

17 Ibidem, p. 35.

18 Idem.

19 Combellas, R., op. cit., p. 36. 
...sobre el concepto de Estado Social de Derecho, la Sala considera que él persigue la armonía entre las clases... A juicio de esta Sala, el Estado Social debe tutelar a personas o grupos que en relación con otros se encuentran en estado de debilidad o minusvalía jurídica, a pesar del principio del Estado de Derecho Liberal de la igualdad ante la ley, el cual en la práctica no resuelve nada, ya que situaciones desiguales no pueden tratarse con soluciones iguales. El Estado Social para lograr el equilibrio interviene no solo en el factor trabajo y seguridad social, ... sino que también tutela la salud, la vivienda, la educación y las relaciones económicas, por lo que el sector de la Carta Magna que puede denominarse la Constitución Económica tiene que verse desde una perspectiva esencialmente social... son elementos inherentes al Estado Social de Derecho, la solidaridad social (artículos 2, 132 y 135 constitucionales) y la responsabilidad social (artículos 2, 132, 135 y 299 constitucionales). De las normas citadas se colige que el Estado Social no sólo crea obligaciones y deberes al Estado, sino que a los particulares también...La corresponsabilidad también se ejerce sobre los ámbitos económico, social, político, cultural, geográfico, ambiental y militar (artículo 326 constitucional)... Luego, el Estado Social de Derecho no sólo crea deberes y obligaciones para el Estado, sino también en los particulares, los cuales - conforme a las normas transcritas - serán de mayor exigencia cuando el sector privado incide en áreas socio-económicas (Tribunal Supremo de Justicia, Sala Constitucional). ${ }^{20}$

La Constitución de 1999 (CRBV) propone un nuevo modelo de Estado, por cuanto se establece como democrático y social de derecho y de justicia; en donde, para Escarrá, lo fundamental es la Justicia, lo cual trae consigo una serie de procesos complejos que "puede atravesar Nación alguna", siendo uno de ellos “...[El] proceso destinado a la reestructuración y reorganización, e incluso, en nuestro caso, a la refundación de las bases axiológicas, políticas, sociales, económicas y culturales que configuran la noción de nuestro Estado". ${ }^{21}$ Afirma Escarrá ${ }^{22}$ que frente al conflicto histórico entre ley y justicia, la justicia será la que prevalecerá.

En atención de lo que propugna la Constitución expresa Escarrá que “...nuestra Nación posee como valores superiores a la vida, la libertad, la justicia, la igualdad, la solidaridad, la democracia, la responsabilidad social,

20 Tribunal Supremo de Justicia, Sala Constitucional, Sentencia núm. 85, del 24 de enero de 2002, en http://www.tsj.gov.ve/decisiones/scon/Enero/85-240102-01-1274\%20.htm.

21 Escarrá Malavé, C., op. cit., p. 2.

22 Escarrá Malavé, C., op. cit., pp. 2 y 3. 
la ética, el pluralismo político y la preeminencia de los derechos humanos". ${ }^{23}$ De donde, según este autor, la garantía y respeto de dichos postulados axiológicos, es una obligación irrenunciable de todos los órganos que integran y ejercen el poder público en sus diferentes niveles de organización, la cual comparten con la generalidad de las personas que habitan o residen en el territorio venezolano.

En atención a los planteamientos formales, doctrinales y jurisprudenciales, se interpreta que Venezuela se consagra formalmente en un Estado democrático social de derecho y de justicia, en donde el Estado debe garantizar a la sociedad civil la realización efectiva y material de los derechos fundamentales a través de la consagración de unos principios, tales como el de progresividad de la ley, igualdad, subsidiaridad y corresponsabilidad, entre otros. Asimismo, prevé herramientas a través de las cuales la sociedad civil puede plasmar dichos principios. Concretamente en el caso del principio de la corresponsabilidad su materialización puede darse a través de la participación.

La consagración contemplada en la Constitución venezolana de 1999 de esta concepción de Estado, responde, como se señaló antes, a un proceso general teórico de acumulación de modelos de Estado que acaece en los textos constitucionales europeos y latinoamericanos en el siglo XX, puesto que incorpora muy claramente elementos del Estado liberal, del social y del democrático, de manera integrada y en donde la materialización de los derechos y principios fundamentales de los cuales el Estado es el garante, atienden al contexto político, social y jurídico, pero su cumplimiento no es efectivo. ${ }^{24}$

\section{Principios constitucionales en la Constitución de 1999}

La Constitución venezolana de 1999, en el título I contempla a los principios constitucionales. A los efectos de esta investigación se considera el principio de corresponsabilidad, el cual es uno de los tantos principios

23 Véase Ávila Hernández y Martínez de Correa, "Reflexión socio-jurídica sobre los derechos fundamentales prestacionales en Venezuela. Caso: los derechos educativos", Revista Venezolana de Análisis de Coyuntura, vol. VII, núm. 1, enero-julio, pp. 123-144; Brewer-Carías, A., op . cit.; Combellas, R., op. cit.

24 Constitución de la República Bolivariana de Venezuela (CRBV), artículo 4, op. cit. 
rectores previsto en el artículo 4 de la carta magna vigente, y constituye un principio constitucional novedoso.

Establece el artículo 4o.: "La República Bolivariana de Venezuela es un Estado federal descentralizado en los términos consagrados en esta Constitución, y se rige por los principios de integridad territorial, cooperación, solidaridad, concurrencia y corresponsabilidad (CRBV)". ${ }^{25}$

Tal como se señaló antes, la Constitución de 1999 sigue la tradición que predomina en el constitucionalismo contemporáneo al considerar los principios que consagra, en atención del momento histórico, político y social que vive el país. Los principios están dispuestos en la Constitución venezolana de 1999 de manera tal que la transversalizan. ${ }^{26}$

Combellas expresa que aunque puede ser paradójico este texto constitucional es principista, por cuanto "no se contenta nuestra Lex Superior con incorporar en su título primero los principios fundamentales que le ofrecen a su normativa guía y sustentación, sino que a lo largo y ancho de su articulado no sólo se reiteran sino que se suman prolijamente nuevos principios y valores". ${ }^{27}$

Istúriz ${ }^{28}$ expresa que al elaborar una nueva Constitución, los constituyentes partieron de la transversalización axiológica, lo que permite que en la Constitución haya una correspondencia desde el preámbulo hasta las disposiciones finales.

Ello en ocasión, señala Istúriz, de que:

si decimos que necesitamos una Constitución que garantice la democracia, que impulse la participación, donde la gente juegue un papel protagónico, que el hombre sea el centro, esos principios y orientaciones que en cada capítulo, en cada artículo que se desarrolle y elabore, tienen que estar presentes y tenerlos como premisa. ${ }^{29}$

25 Combellas, Ricardo, "El proceso constituyente y la Constitución de 1999”, en Plaza, Elena y Combellas, Ricardo, Procesos constituyentes y reformas constitucionales en la historia de Venezuela: 1811-1999, Caracas, Universidad Central de Venezuela, 2005, t. II, pp. 765-808. Istúriz, A. op. cit. Jaua, Elías, "La sociedad organizada en su papel de corresponsabilidad social", Seminario Democracia, Estado y Ciudadanía, Caracas, Sinergia, Goethe Institut Inter Naciones y Asociación Cultural Humboldt, 21 y 22 de mayo de 2003, en http://abrilonce.tripod.com/texto445.html.

26 Combellas, R. op. cit., p. 788.

27 Istúriz, A., op. cit.

28 Ibidem, p. 4.

29 Combellas, R., op. cit. Brewer Carias, A., op. cit. 
Es así que el texto constitucional vigente considera desde su preámbulo hasta las diferentes disposiciones finales, el desarrollo de los principios fundamentales - entre ellos el principio de corresponsabilidad-, los cuales sustentan el Estado social de derecho y de justicia que consagra. Este principio constitucional se relaciona con la participación de la sociedad civil.

La corresponsabilidad tiene múltiples significados, puede ser vista desde diferentes perspectivas y desde diferentes aproximaciones conceptuales. La acepción que se toma en este trabajo es el de la corresponsabilidad como principio.

A continuación se presenta una aproximación teórica a la corresponsabilidad como principio constitucional y como parte fundamental de lo político.

\section{La corresponsabilidad como principio}

en la Constitución de 1999

La actual Constitucional venezolana de 1999, como se ha señalado, surge de un proceso inédito, trayendo consigo una nueva realidad jurídicoinstitucional, y una serie de principios y valores fundamentales, los cuales recoge y jerarquiza en su Título Primero.

La corresponsabilidad, en la actualidad, se concibe como un principio constitucional del novísimo constitucionalismo social y de la democracia que se puede ejercer, en Venezuela, en los ámbitos económico, social, político, cultural, geográfico y militar; de acuerdo a la Constitución venezolana de $1999 .^{30}$

En este sentido, Combellas entiende que:

la corresponsabilidad es un principio sugerente y novedoso que incorpora en su seno el texto constitucional. Parte del rompimiento de la clásica dicotomía liberal Estado-sociedad civil. La esfera pública no se circunscribe exclusivamente a la burocracia del Estado, pues allí se involucra directamente la sociedad organizada. ${ }^{31}$

La corresponsabilidad es uno de los principios fundamentales que sustenta el modelo de Estado y de sociedad plasmado en la Constitución

${ }^{30}$ Combellas, R., op. cit., p. 2. Brewer Carias A, op. cit.,

31 Camps, Victoria, Elementos históricos del concepto de lo público. V Encuentro Iberoamericano del Tercer Sector, Colombia-Tercer Sector, 2001. Org. http://www.colombia2000.org/las_memorias/lo_publico/memorias_lo_publico.htm, p. 3 . 
vigente, en donde el Estado tiene unas funciones y responsabilidades específicas y los ciudadanos tienen unos derechos y unas obligaciones que cumplir en los asuntos públicos. Si bien el Estado tiene unas responsabilidades y unas funciones, no por ello debe limitar ni restringir a la sociedad; en este sentido, Camps plantea “...la idea de un Estado que no suplante a los individuos cuando estos pueden resolver solos sus problemas". ${ }^{32}$

Para esta autora, el Estado debe garantizar los derechos y a la vez los deberes y obligaciones. Asimismo, debe dispersar el poder que detenga por lo que el Estado no debe temer a "...la dispersión del poder hacia arriba y hacia abajo". ${ }^{33}$ Entendiendo la dispersión hacia abajo, como la posibilidad de acercar la política al ciudadano dando más poder a las políticas locales, delegar el poder político en entidades independientes que promuevan la participación, abrirse a las asociaciones privadas voluntarias.

La corresponsabilidad es un término polisémico, que puede ser vista desde diferentes aproximaciones: como valor o como principio. La noción de corresponsabilidad se fundamenta en una concepción de democracia participativa, en la que la gestión pública no se limita a la gestión de las instituciones del Estado sino que involucra a la sociedad civil en la gestión de lo público. Se entiende lo público como aquello que conviene a todos, o como lo expresan Garcés LLoreda y Buitriago, ${ }^{34}$ la corresponsabilidad es la suma de voluntades, de esfuerzos y de recursos que tienen como meta el diseño y el cumplimiento de reglas que son de interés general.

El valor de la corresponsabilidad, la cual implica la responsabilidad, es un valor social insustituible para la observancia de los derechos humanos, para el debido cumplimiento de las obligaciones de unos en relación con los otros. ${ }^{35}$

32 Camps, Victoria, Elementos históricos del concepto de lo público. V Encuentro Iberoamericano del Tercer Sector, Colombia-Tercer Sector, 2001. Org. http://www. colombia2000.org/las_memorias/lo_publico/memorias_lo_publico.htm, p. 3.

33 Idem.

34 Garcés LLoreda, María Teresa y Tarquino Buitriago, Carlos, "Lo público: una forma de redimensionar el papel del Estado y la sociedad civil en los procesos de control social", Revista Sindéresis, Bogotá, núm. 6, septiembre de 2002, pp. 75-96.

35 Perfecto Sánchez, José Ricardo, La corresponsabilidad, valor social insustituible para la observancia de los derechos humanos, Universidad Autónoma del Estado de 
Para que la corresponsabilidad se dé en la práctica, se debe ser responsable con uno mismo en relación con las otras propias obligaciones de toda clase, por lo que "la corresponsabilidad por lo tanto, presupone la responsabilidad y es un valor más elevado que la responsabilidad. Aquélla, en efecto, asume su compromiso para actuar junto con otros en la construcción de una sociedad más justa...". ${ }^{36}$

Una aproximación teórica al concepto de corresponsabilidad debe partir de una contextualización de la realidad en la que surge este principio y en atención a la relación entre el Estado y la sociedad. En la actualidad se habla de corresponsabilidad porque las esferas de las autonomías ${ }^{37}$ se han interpenetrado. ${ }^{38}$

Luego de la constitucionalización del Estado social, de sus sucesivas transformaciones ${ }^{39} \mathrm{y}$ al superar diferentes aspectos, ${ }^{40}$ se puede hablar de responsabilidades convergentes, concurrentes, compartidas, entre la esfera de la sociedad civil y la esfera del Estado. ${ }^{41} \mathrm{Al}$ punto de encuentro de estas dos esferas (Estado y sociedad) García-Pelayo ${ }^{42}$ le denomina esfera interseccionada.

La forma en que se dé la relación entre Estado y sociedad civil permite que esté presente la corresponsabilidad o no. En la actualidad esta relación atiende a los contextos históricos, políticos, económicos, jurídicos y sociales determinados, $\mathrm{y}$ es en atención a dichos contextos que surge una relación o vínculo entre el Estado y la sociedad que permite la colaboración, la solidaridad y la corresponsabilidad entre éstos. Junto al principio de corresponsabilidad, está entre otros, el de subsidiaridad. ${ }^{43}$

México, 2000, en http://www.Google.es/search?q=cache:gs4LfhZxlcUJ.www.uaemex.mx/ mpaz/articulos 2 .

36 Perfecto Sánchez, José Ricardo, op. cit., pp. 6 y 7.

37 Sobre las autonomías o no de la sociedad civil y el Estado, véase García-Pelayo, 1991, en donde presenta en el t. III, pp. 2969-2980, consideraciones sobre Estado y sociedad, vinculadas a este aspecto de las autonomías.

38 Mascareño, Carlos, Entrevista realizada el 21 de enero de 2005, Barquisimeto.

39 Para ampliar este punto, véase la prolífica obra de Manuel García-Pelayo.

40 Señalados brevemente en esta investigación en el punto sobre Estado social de derecho.

41 Mascareño, C., op. cit.

42 García-Pelayo, Manuel, Obras completas, Madrid, Centro de Estudios Constitucionales. 1991, ts. I, II, III.

43 Rodríguez-Arana Muñoz (2000) entiende que el principio de subsidiariedad permanece en la entraña del Estado social y democrático de derecho, pues confirma la idea 
En esta investigación se parte del replanteamiento de la relación entre el Estado y la sociedad y la forma en que dicha dicotomía se manifiesta en el presente, de cara al devenir jurídico, histórico, social y político. En este sentido, existen planteamientos, estudios, investigaciones, en donde se discute y analiza la relación entre el Estado y la sociedad contemporáneamente. ${ }^{44}$

La sociedad es diferente al Estado, pero ello no quiere decir que necesariamente se opongan. ${ }^{45}$ Por ello, lo difícil de esta relación. ${ }^{46}$ La sociedad civil

de que los poderes públicos, existen para servir al ciudadano y no el ciudadano al Estado. ${ }^{44}$ Iranzo T., Mauricio, "Gobernabilidad y desarrollo", Serie Cuadernos para el Debate, núm. 1o. y 2o., Valencia, Universidad de Carabobo, Facultad de Ciencias Jurídicas y Políticas Venezuela, 2006, pp. 74-81. Mascareño, C., op. cit.; Cunill Grau, Nuria, Entrevista realizada el 2 de febrero de 2005, Caracas; Cunill Grau, Nuria, Repensar lo público a través de la sociedad, Caracas, CLAD-Nueva Sociedad, 1997; Combellas, R., op. cit.; Bresser Pereira, Luíz Carlos y Cunill Grau, Nuria, "Entre el Estado y el mercado: lo público no estatal", en Bresser-Pereira, Luiz Carlos y Cunill Grau, Nuria (eds.), Lo público no estatal en la Reforma del Estado, Buenos Aires, CLAD-Paidós, 1998, pp. 25 y 56. De Sousa Santos, Boaventura, "A Reinvenção Solidária e Participativa do Estado", Seminário Internacional Sociedade e a Reforma do Estado, São Paulo, Brasil, 1998, en http://www.planejamento.gov.br/arquivos_down/seges/publicacoes/reforma/seminario/ Boaventura.PDF. García-Pelayo, M., op. cit.

45 García-Pelayo expresa que la sociología moderna considera a la sociedad en sentido amplio y en sentido restringido. Dentro de los conceptos restringidos de sociedad hay una tendencia a ver en la sociedad formas específicas de convivencia humana "destacadas, precisamente, por su oposición a otras formas de convivencia. Dentro de tales conceptos, los más importantes son el que concibe a la sociedad como algo distinto y aún opuesto al Estado, y el que la concibe como una forma peculiar opuesta a la comunidad", op. cit., p. 2525. García-Pelayo entiende que el modo en que finalmente se defina a la sociedad dependerá de los autores, "pues a la natural y general discrepancias en cuanto a los conceptos fundamentales de las ciencias del espíritu se une, en este caso, la politización del concepto, y con ello su función ideológica, ya que el problema de la relación Estado y sociedad es uno de los temas subyacentes en la dialéctica política desde fines del siglo XVIII hasta el presente", op. cit., p. 2535. Iranzo, Mauricio, "Desarrollo humano y capital social: su incidencia en los procesos de transformación institucional", VI Jornadas de Investigación DAC-UCLA. Barquisimeto. http://www.ucla.edu.ve/dac/vijornadas. Cunill Grau, N., op. cit. Mascareño, Carlos, La relación Estado-sociedad civil a nivel territorial en Venezuela. VI Congreso Internacional del CLAD sobre la Reforma del Estado y de la Administración Pública, Buenos Aires, 5-9 de noviembre de 2001, en http://www.clad. org.velfulltext/0042541.pdf. García-Pelayo, M., op. cit.

46 La relación entre el Estado y la sociedad es compleja. Existe la posibilidad — bajo ciertas condiciones - para que ésta se dé armónicamente, o como señala Cunill (2005) suma positiva (en donde ambos trabajen en pos de objetivos comunes, donde ambos se conviertan en ganadores, en términos de los resultados de esa experiencia). No obstante, no siempre existe la posibilidad de que la relación entre el Estado y la sociedad civil sea 
sirve "...como medio para ampliar y mantener las bases democráticas... la sociedad civil aparece como custodio y proveedor de bienes sociales frente a un Estado que deja de ser el único garante del bien común". ${ }^{47}$

La redefinición de la relación Estado-sociedad plantea una nueva forma de relación y de entendimiento, que se basa en el consenso, en la búsqueda de encuentros, en el establecimiento de metas, objetivos, pretensiones frente a una realidad compleja, heterogénea y contradictoria. ${ }^{48}$

Desde el plano jurídico-formal, la Constitución venezolana de 1999 inscribe su filosofía en valores y principios como la libertad, la igualdad, la justicia, la democracia, todo ello bajo el valor rector de la eminente dignidad de la persona humana. Asimismo, señala Combellas "... dentro de valores y principios de solidaridad, responsabilidad social y corresponsabilidad, que conllevan una colaboración Estado-sociedad civil, no sólo bajo criterios públicos estatales sino también bajo criterios públicos no estatales". ${ }^{49}$

Lo público se aborda, por los estudiosos del tema, desde perspectivas diferentes por la polisemia del término, por las diferentes acepciones. A continuación se hace una aproximación teórica a su concepto, en atención al contexto actual..$^{50}$

suma positiva, porque es una relación que está cruzada por el problema del poder, por el problema de los intereses, lo que puede traer desde conflictos hasta enfrentamientos reales en las relaciones de la sociedad con el Estado (Cunill, 2005).

47 Mascareño, C., op. cit., p. 3.

48 Iranzo T., M., op. cit.

49 Combellas, R., op. cit., pp. 106-108.

50 Mockus, Antanas. "La pregunta por lo público desde la sociedad civil", V Encuentro Iberoamericano del Tercer Sector, Colombia-Tercer Sector, 2001. Org. http://www. colombia2000.org/las_memorias/lo_publico/memorias_lo_publico.htm. Garay S., Jorge, "Una nota sobre la construcción de lo público", V Encuentro Iberoamericano del Tercer Sector, Colombia/Tercer Sector, 2001. Org. http://www.colombia2000.org/las_memorias/lo_publico/memorias_lo publico.htm. Pécaut, Daniel, "La crisis de lo público. Crisis y construcción de lo público", V Encuentro Iberoamericano del Tercer Sector, Colombia-Tercer Sector, 2001, Org. http://www.colombia2000.org/las_memorias/lo_publico/memorias_lo_publico.htm. Cunill Grau, N., op. cit. Bresser Pereira, Luíz Carlos, "Revolución democrática y sociedad civil en América Latina", Desarrollo Humano e Institucional en América Latina, núm. 18, 2001, Instituto Internacional de Governabilidade. Intervention at the seminar. La reinvención de la política y de la ciudadanía: la gobernabilidad democrática para el desarrollo humano en América Latina, Barcelona, Instituto Internacional de Gobernabilidad, en http://www,iigov.org/. Bresser Pereira, Luíz Carlos, "Sociedade Civil: Sua Democratização para a reforma do Estado", en Bresser-Pereira, Luiz Carlos, Wilheim, Jorge y Sola, Lourdes (orgs.), Sociedade e Estado em Transformação, UNESP-ENAP, 1999, pp. 67-116. Bresser Pereira, Luiz Carlos, "Estado, 
Mockus ${ }^{51}$ entiende que lo público encarnó en el Estado, pero al irse transformando, más recientemente, el Estado perdió el monopolio de lo público y se convirtió en el primer y principal actor que se somete al escrutinio público, de donde "adquieren en este contexto un gran sentido las alianzas entre los organismos multilaterales o los gobiernos, nacionales o locales, y las organizaciones de la sociedad civil". 52

Garay S. realiza una aproximación teórica al concepto de lo público, en atención a lo que expresan diferentes autores que tratan sobre el tema, es así que señala que para Rabotnikof(1993) lo público es aquello que es de interés o de utilidad común a todos, lo que concierne al colectivo, lo que atañe a la comunidad y, por ende, a la autoridad de allí emanada, en contraposición de aquello que se refiere a la utilidad y el interés individual; lo público es lo que es visible y se desarrolla a la luz del día, lo manifiesto, lo ostensible en contraposición de aquello que es secreto, preservado oculto, y finalmente lo público es "lo que es común, accesible a todos y por tanto abierto vs. aquello cerrado que se sustrae a la disposición de otros". 53

Para otros autores, expresa Garay S. existe una mayor variedad de sentidos de lo público, algunos de ellos ciertamente ambiguos, que contrastan con el correspondiente sentido de lo privado, "en efecto, el sentido de lo público puede abarcar lo que es relacionado con el Estado; accesible a toda la gente; concerniente a la gente, y pertinente al bien común o al interés compartido (Fraser 1997, p. 85)"..$^{54}$

Para Cunill ${ }^{55}$ y Bresser-Pereira ${ }^{56}$ lo público — entendido como lo que es de todos y para todos - se opone tanto a lo privado como a lo corporativo. Y entienden que dentro de lo público puede distinguirse entre lo público estatal y lo público no estatal. Consideran que la importancia - creciente- que adquiere lo público no estatal se asocia de manera fundamental a la necesidad de proteger los derechos que cada ciudadano tiene, de que el patrimonio público sea de hecho público y no capturado por intereses particulares.

Sociedade Civil e Legitimidade Democrática", Lua Nova-Revista de Cultura e Política, núm. 36, 1995, pp. 85-104.

51 Mockus, A., op. cit.

52 Ibidem, pp. 1-6.

53 Garay S., J., op. cit., p. 1.

54 Idem.

55 Cunill Grau, N., op. cit.

56 Bresser Pereira, L., op. cit. 
Lo público no estatal tiene una doble dimensión: como control social y como forma de propiedad. La separación tradicional en donde se equipara lo público sólo al Estado y se opone a lo privado se hace insuficiente. Es así que el Estado no agota ni representa todo lo público, por cuanto lo público es decir "lo que es de todos y para todos" diferencia entre lo público estatal y lo público no estatal. ${ }^{57}$

De lo que se interpreta, que se presenta en la actualidad una redimensión de lo público en donde se diferencia la esfera de lo público estatal de la esfera de lo público no estatal, tal como lo señalan autores como Iranzo, ${ }^{58}$ Cunill, ${ }^{59}$ Mascareño, ${ }^{60}$ Combellas, ${ }^{61}$ Bresser-Pereira ${ }^{62}$ y De Sousa Santos. ${ }^{63}$ Y es precisamente en la esfera de lo público no estatal en donde la sociedad civil va a tener un ámbito de acción significativo y donde se va a desempeñar, en cuanto y en tanto al principio de corresponsabilidad respecta, así como a la participación como herramienta.

Ahora bien, en este contexto ¿qué se entiende por principio de corresponsabilidad? Combellas considera que "el principio de la corresponsabilidad, es el principio más innovador del novísimo constitucionalismo social", ${ }^{64} \mathrm{y}$ lo define en los términos que lo hace Camps, quien expresa:

Los males sociales, la presencia vacilante e insuficiente de los derechos humanos en la sociedad, son cosas que deben afectarnos a todos, pues todos, de una u otra manera, podemos ayudar a su transformación... no sólo somos responsables de aquellos actos que se nos pueden imputar a cada uno exclusivamente, porque son privados, sino de problemas y conflictos colectivos que piden una solución igualmente colectiva. Hay que repetirlo: todos somos, de alguna manera, responsables de los males de la sociedad. No sólo el Estado, el gobierno, o las anónimas estructuras sociales (Camps citada por Combellas) ${ }^{65}$

\footnotetext{
57 Idem.

58 Iranzo T., M., op. cit.

59 Cunill Grau, N., op. cit.

60 Mascareño, C., op. cit.

61 Combellas, R., op. cit.

62 Bresser Pereira, L., op. cit.

63 De Sousa Santos, B., op. cit.

${ }^{64}$ Combellas, R., op. cit., p. 9.

65 Ibidem, p. 39.
} 
La corresponsabilidad abarca como actores al Estado y a la sociedad civil, — desde la perspectiva que se asume en esta investigación y en atención a lo que se interpreta de los planeamientos que se señalan antes - los cuales comparten responsabilidades para procurar el bienestar de la sociedad misma, de manera que se superen los diferentes conflictos, problemas y carencias que le aquejan.

La corresponsabilidad conjura esfuerzos desde los ámbitos que le son propios al Estado y a la sociedad civil, para alcanzar el bienestar común y el desarrollo humano de la sociedad venezolana en general. Esto de cara a la nueva forma en que se relacionan Estado y sociedad civil de acuerdo a lo que contempla la Constitución venezolana de 1999.

La corresponsabilidad no implica renuncia o abandono gubernamental de las competencias que la Constitución y el régimen jurídico venezolano le asignan a las diferentes instancias institucionales del Estado venezolano, ni significa tampoco que la sociedad civil sustituya a las autoridades y mucho menos que deben asumir obligaciones que le corresponden al Estado, esto es lo que se interpreta de los documentos —entre ellos la Constitución venezolana de 1999) - y de lo que expresan los entrevistados, respecto al principio de corresponsabilidad y el rol del Estado y de la sociedad civil frente a este principio.

La corresponsabilidad busca obtener resultados que mejoren el nivel de vida de todos los ciudadanos con la actuación conjunta y responsable tanto del Estado como de la sociedad civil, en aras de alcanzar el desarrollo humano de manera integral y con equidad en el marco de la normativa constitucional vigente. Ello puede darse a través de herramientas, tal como la participación.

\section{La corresponsabilidad como parte}

\section{fundamental de lo político}

La corresponsabilidad implica una verdadera transformación social de un país y la construcción de un proceso social en donde se conjuguen valores y modos de aprehensión de la realidad política, social, jurídica, en atención a un contexto histórico dado.

La auténtica vida democrática exige la creación de espacios permanentes para que los sectores sociales participen en el diseño, aplicación y control de 
las políticas públicas, especialmente en áreas como la educación, la salud, la seguridad, la protección civil, entre otras. Para ello es indispensable que se coordinen esfuerzos y se colabore entre las instancias institucionales estatales y la sociedad civil en procura de la concreción del principio de corresponsabilidad. ${ }^{66}$

Esto se vincula a una cultura de la corresponsabilidad para el logro de metas u objetivos comunes. De esta cultura de la corresponsabilidad, se debe apropiar tanto la sociedad civil como el Estado, en ocasión de la dinámica que deviene en lo social, jurídico, político y económico en los últimos años.

Con el devenir histórico, contemporáneamente el Estado y la sociedad civil se han transformado, así como la forma en que estos se relacionan, en donde, como señala García-Pelayo, ${ }^{67}$ una parte de las organizaciones sociales participa - de una u otra manera - en la formación y contenido de las decisiones y acciones del Estado y en la que el Estado incide directa o indirectamente en la esfera social sin necesidad de incorporarla a su propio ámbito. Esta relación genera, lo que García-Pelayo denomina "un territorio común o interseccionado... cuyo ámbito puede ampliarse o contraerse según las coyunturas...". ${ }^{68}$

El principio de corresponsabilidad tiene como precepto el trabajo coordinado entre las diferentes instancias institucionales estatales - en sus diferentes niveles - y la sociedad civil.

La sociedad civil debe desarrollar capacidades, habilidades y conocimientos que le permitan alcanzar beneficios sociales y cambios en sus condiciones de vida, en su manera de concebir la realidad y de verse a sí misma como actores políticos verdaderos, debe empoderarse de lo público. El Estado debe compartir la actividad política con la sociedad. Para Combellas, "el Estado no absorbe toda la actividad política, aunque sí recaba una importante función en ella" ${ }^{69}$ Allí reside la corresponsabilidad vista como parte fundamental de lo político, por cuanto la actividad política no se limita a la actividad estatal.

66 Combellas, R., op. cit.

67 García-Pelayo, M., op. cit.

68 Ibidem, p. 2979.

${ }^{69}$ Combellas, Ricardo, Estado de derecho. Crisis y renovación, Caracas, Editorial Jurídica Venezolana, Colección Estudios Jurídicos, núm. XLVI, 1990. p. 101. 


\section{EL PRINCIPIO DE CORRESPONSABILIDAD \\ EN LA CONSTITUCIÓN VENEZOLANA DE 1999}

La nueva realidad jurídico-institucional de Venezuela tiene sus antecedentes inmediatos en dos Constituciones que forman parte de lo que Combellas ${ }^{70}$ denomina la frondosa trayectoria constitucional de Venezuela: la Constitución de 1947: "primera Constitución democrático-social venezolana, donde se abre democráticamente la participación popular y se reconocen los derechos sociales del pueblo venezolano". ${ }^{71}$ y la Constitución de 1961: “...la de más larga duración de nuestra historia republicana, se erigió en el marco institucional de la experiencia democrática que se inaugura en el país el 23 de enero de $1958 " .{ }^{72}$

Ahora bien, ¿Cómo contempla la corresponsabilidad la Constitución venezolana de 1999 (CRBV, 1999)? Para ello en este punto, se estudia el principio de corresponsabilidad de la sociedad civil venezolana actualmente previsto - como innovación constitucional- en la Constitución vigente, todo ello, en atención a las realidades concretas a las que atiende esta Constitución.

\section{La corresponsabilidad como principio en la Constitución venezolana de 1999}

La Constitución de 1999 en su parte dogmática establece los principios fundamentales que comprometen el desarrollo orgánico del propio texto constitucional y el posterior desarrollo legislativo nacional, estadal y municipal.

La corresponsabilidad se consagra en la Constitución venezolana de 1999 , por vez primera, como principio fundamental y atiende a la concepción de Estado social de derecho y de justicia que ella proclama, así como al sistema de gobierno propuesto: democrático participativo.

El principio de corresponsabilidad establece la relación entre el Estado y sus instituciones, independientemente de la rama del poder público y

70 Combellas, Ricardo, "Representación versus participación en la Constitución de la República Bolivariana de Venezuela. Análisis de un falso dilema”, en Salamanca, Luis y Viciano Pastor, Roberto (coords.), El sistema político en la Constitución Bolivariana de Venezuela, Venezuela, Vadell Hermanos, 2003.

71 Ibidem, p. 17.

72 Ibidem, p. 18. 
del nivel de organización político-territorial, con la sociedad venezolana, en donde comparten responsabilidades, entre ellas, la de hacer cumplir la Constitución y las leyes. ${ }^{73}$

En ocasión al principio de corresponsabilidad la sociedad venezolana en su conjunto debe aportar sus esfuerzos para darle validez a la letra y al espíritu de las disposiciones constitucionales y legales de la República Bolivariana de Venezuela, así mismo debe participar para alcanzar el bienestar social general. La Constitución de 1999 prevé a la participación como herramienta que coadyuva a la sociedad a que realice, a que concrete el principio de corresponsabilidad.

En este sentido, la Constitución venezolana de 1999, si bien inscribe su filosofía de los derechos humanos dentro de valores y principios "clásicos" (la libertad, la igualdad, la justicia, la democracia, entre otros) $)^{74}$ también atiende a principios más innovadores como la solidaridad, la responsabilidad social y la corresponsabilidad, esto trae como consecuencia la colaboración entre el Estado y la sociedad.

En este orden de ideas, la concepción de deberes como correlativos a los derechos, se recoge por parte del constituyente de 1999, en atención a la Declaración Universal de Derechos Humanos (1948) en su artículo 29, numeral 1 "Toda persona tiene deberes respecto a la comunidad, pues sólo ella puede desarrollar libre y permanentemente su personalidad"; es así como se consagra uno de los principios esenciales de orden constitucional, el principio de alteridad. ${ }^{75}$

73 Fermín, Enrique. "Observaciones sobre el principio de corresponsabilidad en la CRBV", 2007, en http://64.233.169.104/search?q=cache:6pm4aHHwXlMJ:www.pgr. gob.ve/Doctrinas/Opiniones/opiniones $2 . h t m+$ corresponsabilidad\&hl $=e s \& c t=c l n k \& c$ $d=4 \& g l=v e$. Casal, Jesús María y Chacón, Alma (coods.), op. cit. Mascareño, C., op . cit. Cunill Grau, N., op. cit. Zambrano Constanzo, Alba, "Participación y empoderamiento comunitario: rol de las metodologías implicativas", X Congreso Internacional del CLAD sobre la Reforma del Estado y de la Administración Pública, Santiago, Chile, 18 - 21 de octubre de 2005, en http://www.iij.derecho.ucr.ac.cr/archivos/documentacion/inv\%20otras\%20entidades/CLAD/CLAD\%20X/documentos/zambrcon.pdf. Combellas, R., op. cit.

74 Idem.

75 El principio de alteridad implica que todo derecho comporta una obligación y que todo titular de un derecho tiene necesariamente relación con un sujeto obligado. Para ampliar sobre el principio de alteridad en la Constitución venezolana de 1999, el cual no es objeto de análisis en este trabajo, véase Brewer-Carias, "Reflexiones críticas sobre la Constitución de Venezuela de 1999”, Revista de Derecho Público, Caracas, núm. 81, enero-marzo de 2000, pp. 7-21. 
De igual forma y tal como lo plantea Fermín, el principio de corresponsabilidad "...se encuentra enmarcado dentro del texto constitucional, en varios de sus artículos, formando parte o manifestación del Decreto a la participación, sin que ello excluya otras expresiones, como consecuencia del principio de la concurrencia...". ${ }^{76}$

Al revisar el texto de la Constitución venezolana de 1999, se observa que el principio de corresponsabilidad — principio constitucional fundamental — efectivamente está presente en diferentes artículos, tanto en el Preámbulo como en los títulos: I, III, IV, VII, VIII y IX. Se relaciona así la corresponsabilidad con los ámbitos económico, político, social, cultural, geográfico y militar. Esta presencia a lo largo del texto constitucional atiende a la transversalización axiológica antes referida en esta investigación.

Los artículos que contemplan el principio de corresponsabilidad son: En el título I (Principios fundamentales), el artículo 4. En el título III (De los Derechos Humanos y Garantías, y de los Deberes) el artículo 62 (Capítulo IV. De los Derechos Políticos y del Referendo Popular. Sección Primera. De los Derechos Políticos), los artículos 79, 83, 84, 87 (Capítulo V. De los Derechos Sociales y de las Familias); el artículo 102 (capítulo VI. De los Derechos Culturales y Educativos; el artículo 126 (capítulo VIII. De los Derechos de los Pueblos Indígenas); el artículo 127 (capítulo IX. De los Derechos Ambientales); el artículo 130 (capítulo X. De los Deberes); los artículos 131, 132, 134, 135 (capítulo X. De los Deberes).

En el título IV (Del Poder Público), el artículo 184 (capítulo IV. Del Poder Público Municipal). En el título VII. (De la Seguridad de la Nación) el artículo 326 (Capítulo II. De los Principios de Seguridad de la Nación). En el título VIII (De la Protección de esta Constitución), el artículo 333 (capítulo I. De la Garantía de esta Constitución). Y en el título IX (De la Reforma Constitucional), el artículo 350 (capítulo III. De la Asamblea Nacional Constituyente).

Se interpreta que en el texto de la Constitución de 1999, las frases constitutivas del Preámbulo tienen como pretensión recrear la institucionalidad de la nación a través de la refundación de la República. ${ }^{77}$

76 Fermín, Enrique L., op. cit., p. 1.

77 Lo que reafirman los constituyentistas de 1999 en la Exposición de Motivos, en donde expresamente señalan “...una de las principales motivaciones expresadas en el Preámbulo, es decir, el fin supremo de refundar la República para establecer una sociedad democrática. Ya no sólo es el Estado el que debe ser democrático, sino también la so- 
Asimismo, como señala el Preámbulo, se entiende que es para “...establecer una sociedad democrática, participativa y protagónica, multiétnica y pluricultural en un Estado de justicia, federal y descentralizado", a través de los valores, principios y fines que se establecen en la Constitución de 1999. Uno de estos principios que rige a la República, y el cual es una innovación, es el principio de corresponsabilidad, previsto en el título I, que trata sobre los Principios fundamentales, en su artículo 4. Este principio conlleva a una colaboración entre Estado-sociedad civil bajo criterios públicos estatales y públicos no estatales.

El título III trata de los derechos y deberes fundamentales de los venezolanos. Específicamente, en el ámbito político, el artículo 62, objeto del presente análisis, establece con el novísimo tratamiento constitucional de la participación, que tanto el Estado como la sociedad civil deben facilitar la generación de las condiciones más favorables para la práctica de la participación, es decir, que tanto el Estado como la sociedad civil deben corresponsablemente cumplir con este deber.

En el ámbito social (trabajo, salud), concretamente los artículos 79, 83, 84 y 87, son los que guardan relación con la corresponsabilidad. En este sentido, el artículo 79 al prever "El Estado, con la participación solidaria de las familias y la sociedad...”, establece la actuación corresponsable entre Estado y sociedad, en donde ambos tienen que actuar para lograr un objetivo común que en general es en pro de una sociedad mejor. En el cuanto a la corresponsabilidad en el ámbito de la salud, los artículos 83 y 84 proclaman también de manera novedosa, deberes formales tanto para el Estado venezolano como para la sociedad, en donde éstos deben actuar conjuntamente para la concreción de los derechos y satisfacción de las necesidades de la sociedad en materia de salud.

Asimismo, en cuanto a los derechos educativos, en el artículo 102 se reconoce el derecho a la educación como derecho humano fundamental. Se fortalece el Estado docente no así la sociedad docente, por cuanto no se establece “....un mayor protagonismo de la sociedad civil bajo criterios públicos no estatales... lo que afortunadamente no está vedado en la Constitución". ${ }^{78}$ Ello en atención, a la transversalización axiológica de la Constitución de los principios, así como a los avances en materia de derechos humanos. ${ }^{79}$

ciedad. Siendo democrática la sociedad, todos los elementos que la integran deben estar signados por los principios democráticos y someterse a ellos", op. cit.

${ }^{78}$ Combellas, R., op. cit., p. 88.

79 Idem. 
No obstante a las consideraciones antes expresadas, la corresponsabilidad entre el Estado y la sociedad civil también está presente en este artículo.

Por su parte, el artículo 127 prevé entre otros aspectos, lo referente a la corresponsabilidad entre el Estado y la sociedad en la protección y preservación del medio ambiente.

Los artículos 126, 130,131, 132, 133, 134 y 135, en consonancia con la necesidad de obtener eficacia de los derechos, la realización del principio de supremacía normativa y el respeto al orden público interno venezolano, establecen un grupo de deberes constitucionales - o conductas exigidas para con la sociedad - entre los que merecen citarse el deber de honrar y servir a la Patria, sus valores y símbolos, así como proteger su soberanía e integridad territorial (artículo 130), cumplir y acatar la Constitución y las leyes (artículo 131), de coadyuvar con sus contribuciones a los gastos públicos (artículo 133), a prestar los servicios civil, militar y electorales (artículo 133), así como el de cumplir sus responsabilidades sociales y participar solidariamente en la vida política, civil y comunitaria del país (artículos 132 y 135).

Se interpreta que la sociedad civil tiene estos deberes formales que comparte con el Estado, en cuanto a gestión de lo público, en donde tienen como premisa los valores de la equidad y la justicia. Se comparte la responsabilidad por la gestión entre el Estado y la sociedad civil, y esta responsabilidad deja de ser exclusiva del Estado. Se da paso así, a la noción de corresponsabilidad de donde la sociedad civil debe cumplir de manera responsable con el Estado los deberes que formalmente se le establecen.

Por su parte, el artículo 326 de la Constitución desarrolla la seguridad como una corresponsabilidad entre Estado y sociedad civil para cumplir con los principios de independencia, democracia, igualdad, paz, libertad, justicia, solidaridad, promoción y conservación ambiental y defensa de los derechos humanos, así como para lograr la satisfacción progresiva de las necesidades de la población. Esta corresponsabilidad abarca los ámbitos económico, social, político, cultural, geográfico, ambiental y militar. Dentro de estos amplios enunciados se concibe la seguridad en una doble faz de protección de principios y derechos y de cobertura de necesidades indefinidas, aunque, cuando se indican las instancias garantes y los responsables operativos, el concepto se restringe notablemente, tal como señala Gabaldón. ${ }^{80}$

80 Gabaldón, Luis Gerardo, "Seguridad ciudadana, confianza pública y policía en Venezuela", Revista Venezolana de Economía y Ciencias Sociales, Caracas, vol. 13, núm. 3, diciembre de 2007. 
El artículo 333 establece, como lo hacía el artículo 250 de la Constitución de 1961, el deber que tienen los venezolanos de "colaborar en el restablecimiento y efectiva vigencia" de la Constitución. Finalmente, el artículo 350 también se refiere a la corresponsabilidad del pueblo venezolano. ${ }^{81}$

En atención al análisis e interpretación de la Constitución venezolana de 1999 (CRBV, 1999) — a los artículos que guardan relación con el principio de corresponsabilidad-, al contexto histórico, jurídico, político, social concreto, a las posiciones doctrinarias, se entiende que la corresponsabilidad contemplada como principio constitucional, prevé la colaboración entre el Estado y la sociedad civil, de manera que conjuguen esfuerzos desde sus propios espacios para alcanzar el bienestar social general del pueblo venezolano y por ende el desarrollo humano.

La corresponsabilidad no se debe entender negativamente, no se debe tomar como la posibilidad del Estado de abstenerse, de renunciar, de abandonar las diferentes potestades y obligaciones que formalmente tiene. Tampoco como la posibilidad de que el Estado "obligue a colaborar", en ocasión de este principio a la sociedad civil, en la ejecución de políticas estatales que vulneren los derechos humanos. En cuanto a la sociedad civil, esta no va a sustituir al Estado, ni va a desplazarlo en sus obligaciones, tal como se señaló antes.

Corresponsabilidad es construir una cooperación responsable, consciente y respetuosa de la independencia - tanto del Estado como de la sociedad civil - para procurar frutos que optimicen el nivel de vida y de bienestar social de todos y cada uno de los venezolanos, en atención al respeto de la carta magna.

\section{REFLEXIONES FINALES}

En cuanto a la doctrina particular del Estado venezolano, emerge del análisis que tanto en lo institucional como en lo jurídico, en Venezuela - en atención a la consagración actual en la Constitución venezolana de

81 Sobre las discusiones e interpretaciones que se le dan al artículo 350, en cuanto a si consagra o no la desobediencia civil, por no ser el objeto de análisis de esta investigación, se recomienda revisar: a) Sentencia de Sala Constitucional del Tribunal Supremo de Justicia, del 22 de enero de 2003, Expediente 02-1559, en ocasión de Recurso de Interpretación del Artículo 350 de la Constitución; b) Chacín Fuenmayor. "Algunos aspectos teóricos de la desobediencia civil: análisis sobre su consagración en la Constitución venezolana", FRONE, vol. 10, núm. 2, agosto de 2003, pp. 49-72, entre otras. 
1999 — están previstos los derechos individuales y los derechos sociales en un marco regulatorio constitucional y legal que prevén los medios, vías e instrumentos a través de los cuales pueden concretarse estos derechos. Considera también la carta magna, la corresponsabilidad como principio.

En cuanto a los principios que la Constitución de 1999 contempla, está el principio de corresponsabilidad, el cual está asociado al Estado social de derecho e involucra al Estado y a la sociedad civil en la responsabilidad de los asuntos públicos, los cuales no le conciernen exclusivamente al Estado sino que exigen la participación de la sociedad civil. Pero la carga, la responsabilidad de regulación del hecho social sigue en cabeza del Estado. Esta vinculación surge en razón del actual contexto histórico, político, jurídico, económico y social, de donde se redimensiona la relación entre el Estado y la sociedad con base al planteamiento constitucional vigente.

Ello en ocasión de que en la actualidad la relación entre el Estado y la sociedad civil atiende a una realidad compleja que plantea la corresponsabilidad entre éstos, y así lo prevé la Constitución venezolana de 1999, por cuanto lo público (lo cual se entiende como lo público estatal y lo público no estatal) no se encarna sólo en el Estado sino que también en la sociedad civil. Es precisamente en la esfera pública no estatal, en donde la sociedad civil tiene su ámbito de acción, en cuanto y en tanto al principio de corresponsabilidad se refiere, puesto que la corresponsabilidad es una de las formas a través de las cuales se puede traducir la relación entre el Estado y la sociedad civil, pero no la única ni la última. ${ }^{82}$

Se entiende que el concepto de corresponsabilidad considera a la dinámica de la transformación tanto del Estado como de la sociedad, y a la relación entre el Estado y la sociedad civil, en atención al marco del desarrollo histórico, político, jurídico concreto; lo cual deviene en una cultura de la corresponsabilidad de la cual se apropian tanto la sociedad civil como el Estado.

Así mismo, emerge del análisis que la corresponsabilidad busca mejorar el nivel de vida de los ciudadanos en ocasión de la actuación conjunta y responsable del Estado y la sociedad civil en aras de conseguir el desarrollo humano en el marco de la normativa constitucional venezolana vigente. Por lo que la sociedad civil —en atención a las capacidades, habilidades y conocimientos - alcanza beneficios sociales y cambios en sus condiciones de vida, en su forma de concebir la realidad y de verse a sí misma como una verdadera actora política, al empoderarse de lo público. En este sen-

${ }^{82}$ Cunill, N., op. cit. 
tido, el empoderamiento es el proceso de reducción de la vulnerabilidad y de crecimiento de las propias capacidades de la sociedad civil en general, que conducen a la promoción y concreción del desarrollo humano a través de la participación. El Estado, por su parte, comparte la actividad política con la sociedad.

La corresponsabilidad implica un compromiso del Estado así como la participación de la sociedad. En este sentido, el Estado, justificándose en la existencia del principio de corresponsabilidad, no puede evadir el ejercicio de sus funciones públicas y burlar sus deberes, alegando como excusa que la sociedad no ha cumplido con su parte. El principio de corresponsabilidad supone una cooperación responsable, consciente y respetuosa de la independencia del Estado y de la sociedad civil, que procura la optimización del nivel de vida y de bienestar social de los venezolanos, en donde se pueda alcanzar el desarrollo humano como noción integral del desarrollo.

Fecha de recepción: 5 de abril de 2011.

Fecha de dictamen: 8 de junio de 2011. 